\title{
Feedback Analysis of Test Anxiety and Academic Performance Among Students
}

John Pastor Ansah, Signature Program in Health Services and Systems Research, Duke-NUS Graduate Medical School, Singapore Jing Xin Leow, Faculty of Arts and Social Sciences (Economics), National University of Singapore, Singapore

\begin{abstract}
Previous research has shown that test anxiety among students affects academic performance. Understanding the feedback mechanisms underlying the dynamics of test anxiety and academic performance among students will inform the development of interventions to cut the prevalence of text anxiety. Many theories have been proposed to explain the underlying causes of text anxiety and academic performance. In this research, the authors sought to synthesize the dominate theories of test anxiety and academic performance (i.e., cognitive attention model, learning deficit model, dual deficit model, and social learning model) and translate it into an explicit system dynamic simulation model that captures the main feedback loops. Simulation experiments were implement using synthetic data and variation of few parameters in the experiments produced realistic trajectories of students' academic performance.
\end{abstract}

\section{KEYWORDS}

Academic Performance, Feedback Analysis, System Dynamics, Test Anxiety

\section{INTRODUCTION}

In most schools, standardized tests and examinations have been the default for measuring students' learning and understanding of course material. While Singaporean students fare better than their peers from other countries in academic performance, it pays in emotional price as they experience high levels of anxiety, as concluded by a study by Organization of Economic Cooperation and Development (Davie, 2017). Against a competitive backdrop where students are expected not only to perform well but do better than their peers, they are exposed and vulnerable to anxiety, in particular, test anxiety. Sansgiry and Sail (2006) define test anxiety as the "reaction to stimuli that are associated with an individual's experience of testing and evaluative situations". When unchecked, this overstimulation causes mental distress and fear in students, inhibiting their way of thinking and by interacting with other factors, thereby affecting their academic performance in the next test. This becomes a stressor and the cycle repeats. We believe that to understand the dynamic impact of test anxiety on academic performance of students, particularly on developing interventions to avoid unhealthy test anxiety, it would be valuable to develop a conceptual model that represents our hypotheses about the dynamic feedback mechanisms of test anxiety and academic performance among students. Systems simulation 
model (Ansah, 2017; Zelinka, 2019; Bhushan, 2017) provides valuable insights into dynamically complex phenomenon such as test anxiety and academic performance and allows for the generation of testable hypothesis and identification of leverage points for interventions.

In this research, we develop a system dynamics model that captures our understanding of the feedback mechanisms of test anxiety, how it affects academic performance in students and how we can intervene to mitigate the problem.

\section{LITERATURE REVIEW}

Past research has shown that test anxiety affects academic performance (Benjamin, 1991; Wittmaier, 1972; Kirkland and Hollandsworth, 1979; Meichenbaum and Butler, 1980; Kalechstein et al, 1988). Many theories have been proposed to explain the phenomenon of test anxiety; of which, the four dominate models are discussed herein.

\section{Cognitive-Attention Model}

As the first model to appear in the literature (Benjamin, 1991), the cognitive-attention model proposes that cognitive factors, such as student negative evaluation and self-perceived inadequacies, and emotionality factors, such as physiological reactions of distress and tension, manifest in the form of task-irrelevant thinking, worry, negative self-preoccupations or physiological reactions (Sarason, 1978, 1980; Wine, 1971; Jones \& Petruzzi, 1995). As such, anxious individuals allocate attentional resources to the perceived threat, rather than focusing on the task at hand. This disrupts the balance between the two attentional systems (Cobetta \& Shulman, 2002; Posner \& Peterson, 1990), thereby decreasing the influence of goal-directed attentional system (Eysenck, 2007).

\section{Learning Deficit Model}

This model challenges the cognitive-attention model by suggesting that deficient test-taking skills and inadequate study habits are the main causes of poor performance instead of anxiety. Backed by Wittmaier (1972), Kirkland and Hollandsworth (1979), it was discovered that students with high levels of test anxiety are less equipped with effective study habits as opposed to students with low levels of test anxiety. They posit that the sole reason for poor academic performance is poor study and test-taking skills in students with test anxiety levels.

\section{Dual Deficit Model}

The dual deficit model acknowledges the cognitive-attention factor and the learning deficit in students with high test anxiety. Proponents such as Meichenbaum and Butler (1980) suggest that a student with high test anxiety may have "poor study skills, task-irrelevant dialogue, irrational beliefs and unrealistic expectations", which interact with one another and thus attribute to failure to organise academic content and difficulties in retrieving such information during the test.

\section{Social Learning Model}

Based on traditional social learning theories, the social learning model is centred on the concepts of self-esteem and expectancy outcomes from external reinforcements such as luck, and fate (Kalechstein et al, 1988). According to Kalechstein, many studies have proven that students with high performance are positively oriented to their achievement whereas students with low performance tend to "convey a sense of hopelessness". The high correlation between self-efficacy and achievement and self-esteem is hence an integral variable that affects a student's behaviour and hence amount of effort and persistence for a task (Schwarzer and Jerusalem, 1989). 
Table 1. List of test anxiety theories and its concepts

\begin{tabular}{|l|c|c|c|c|}
\hline \multicolumn{1}{|c|}{ Concepts } & $\begin{array}{c}\text { Cognitive } \\
\text { Attention }\end{array}$ & $\begin{array}{c}\text { Learning } \\
\text { Deficit }\end{array}$ & Dual Deficit & $\begin{array}{c}\text { Social } \\
\text { Learning }\end{array}$ \\
\hline Self-evaluation & $\sqrt{ }$ & & & $\sqrt{ }$ \\
\hline Self-perceived inadequacy & $\sqrt{ }$ & & $\sqrt{ }$ & $\sqrt{ }$ \\
\hline Emotionality & $\sqrt{ }$ & & $\sqrt{ }$ & \\
\hline Task irrelevant behaviour & $\sqrt{ }$ & & $\sqrt{ }$ & \\
\hline Task relevant behaviour & $\sqrt{ }$ & & $\sqrt{ }$ & \\
\hline Test taking skills & & $\sqrt{ }$ & & \\
\hline Test anxiety & & $\sqrt{ }$ & $\sqrt{ }$ & $\sqrt{ }$ \\
\hline Performance & $\sqrt{ }$ & $\sqrt{ }$ & $\sqrt{ }$ & $\sqrt{ }$ \\
\hline Expected performance & & & & \\
\hline
\end{tabular}

Table 1 shows the four main test anxiety models and the concepts from each model used in developing our systems model in our effort to map out the dynamics feedback mechanisms that explain test anxiety and academic performance of students.

\section{METHODS}

The systems modelling methodology of system dynamics that focuses on capturing causal relationships and dynamic feedback mechanisms of different concepts and part of a system (Sterman, 2001; Nasution, 2018; Al-Kadeem, 2017) was used. Based on extensive literature review and discussions, a conceptual system dynamics model was developed to capture the hypothesized relationships between the key concepts derived from the four main models of test anxiety (cognitive attention, learning deficit, dual deficit, and social learning) that explains the dynamic interactions between test anxiety and academic performance of students. Subsequently, the conceptual model was discussed extensively to verify that the structure and assumptions regarding causal relationships are plausible and have face validity. The model was refined following several discussions until it was deemed to be sufficiently robust concerning its ability to capture the purpose of the model. Finally, the model was parameterized with synthetic data to simulate plausible trajectories of students under different scenarios.

\section{Model Components and Parameters}

Figure 1 shows the test anxiety and academic performance model, which consist of many variables/ concepts. In the context of this model, we define these variables/concepts as follows:

- Performance: Performance refers to students' academic performance in school, which is commonly assessed by examinations. These exams score students on a series of questions, depending on the subject of assessment. For example, the Organisation of Economic Cooperation and Development (OECD) uses the Program for International Student Assessment (PISA) as a scale to measure reading literacy, mathematical literacy, and scientific literacy. The domain of reading literacy tested students on their abilities to access and retrieve information, to integrate and interpret texts, and thereby to reflect and evaluate them. Similarly, mathematical literacy tested students on their abilities to formulate situations mathematically, to employ mathematical concepts, facts, procedures, and reasoning, as well as to interpret, apply and evaluate mathematical outcomes. Scientific literacy tested students on their abilities to explain a phenomena scientifically, to evaluate and design scientific enquiry, as well as to interpret 
scientific data. Using a series of questions, schools score students, which is then translated into a grade point average for the student. The test anxiety and academic performance model has three different types of performance: average expected performance, current performance, and actual performance. Expected performance is the average performance a student expect of him/ herself at the end of an examination period. It is the desired performance. It could be realistic or unrealistic given the aptitude of the student. Current performance is the performance of a student from a specific examination. Average actual performance is the average performance from all exams taken by a student.

- Self-evaluation: Self-evaluation refers to the evaluation of oneself positively or negatively. Hence, a student with a higher self-evaluation will have a positive evaluation of himself, whereas a student with a lower self-evaluation will have a negative evaluation. Self-evaluation can be measured by the Rosenberg's Self-Esteem Scale (Rosenberg, 1965) to assess a student's self-evaluation. The Rosenberg's Self-Esteem Scale measures global self-worth through ten questions regarding both positive and negative feelings about the self. As a uni-dimensional scale, it sums the score for each question to indicate the level of self-esteem and hence self-evaluation of an individual (Table 2).

Table 2. The pathways of feedback loops

\begin{tabular}{|l|l|}
\hline \multicolumn{1}{|c|}{ Feedback Loop } & \multicolumn{1}{c|}{ Paths } \\
\hline Self-evaluation influence performance $(\boldsymbol{R} 1)$ & $1 \rightarrow 2 \rightarrow 8 \rightarrow 9 \rightarrow 11 \rightarrow 12 \rightarrow 13 \rightarrow 16 \rightarrow 17 \rightarrow 1$ \\
\hline past performance $(\boldsymbol{R} 2)$ & $1 \rightarrow 16 \rightarrow 17 \rightarrow 1$ \\
\hline Task irrelevant $(\boldsymbol{R} 3)$ & $12 \rightarrow 13 \rightarrow 19 \rightarrow 21 \rightarrow 22 \rightarrow 24 \rightarrow 25 \rightarrow 11 \rightarrow 12$ \\
\hline Task relevant $(\boldsymbol{R} 4)$ & $12 \rightarrow 13 \rightarrow 19 \rightarrow 21 \rightarrow 23 \rightarrow 24 \rightarrow 25 \rightarrow 11 \rightarrow 12$ \\
\hline Shifting expectation $(\boldsymbol{B} \mathbf{1})$ & $2 \rightarrow 8 \rightarrow 9 \rightarrow 11 \rightarrow 12 \rightarrow 5 \rightarrow 3 \rightarrow 2$ \\
\hline
\end{tabular}

- Self-perceived inadequacy: Self-perceived inadequacy refers to an individual's perceived self-worth and feelings of inadequacy and incompetence. An individual with high feelings of inadequacy is likely to have a lower ability to maintain interpersonal relations and succeed in work and school. Self-perceived inadequacy can be estimated in practice using the Janis-Field Feelings of Inadequacy Scale (Janis and Field, 1959). The Feelings of Inadequacy Scale uses a series of questions to measure the confidence and feelings of self-worth of an individual.

- Emotionality: Emotionality, otherwise known as physiological over-arousal, is experienced when a student is overcome with sudden intense fear, resulting in symptoms such as difficulty breathing, increased heart rate, sweating and extreme discomfort as a result of the inability to handle high levels of stress.

- Test-taking skills/ mastery: This measures the ability of a student to perform in a test, affecting his actual performance thereafter. Test-taking skills are determined by the amount of time and effort expended by a student in preparing for an exam.

- Test anxiety: Test anxiety refers to the combination of worry and dread in combination of physiological arousal under a test stressor, resulting in poor performance. During a test, students with test anxiety will experience feelings of fear, dread, tension and display other somatic symptoms. Test anxiety could be measured with the Westside Test Anxiety Scale (Driscoll, 2007), which is utilised to gauge the level of nervousness of a student during test/exam.

The structure of the test anxiety and academic performance model represents the interactions between the key variables/concepts described in detail earlier. The model equations and input parameters are available in the appendix. Because students are assessed based on their test score, we 
Figure 1. Test Anxiety and academic performance model

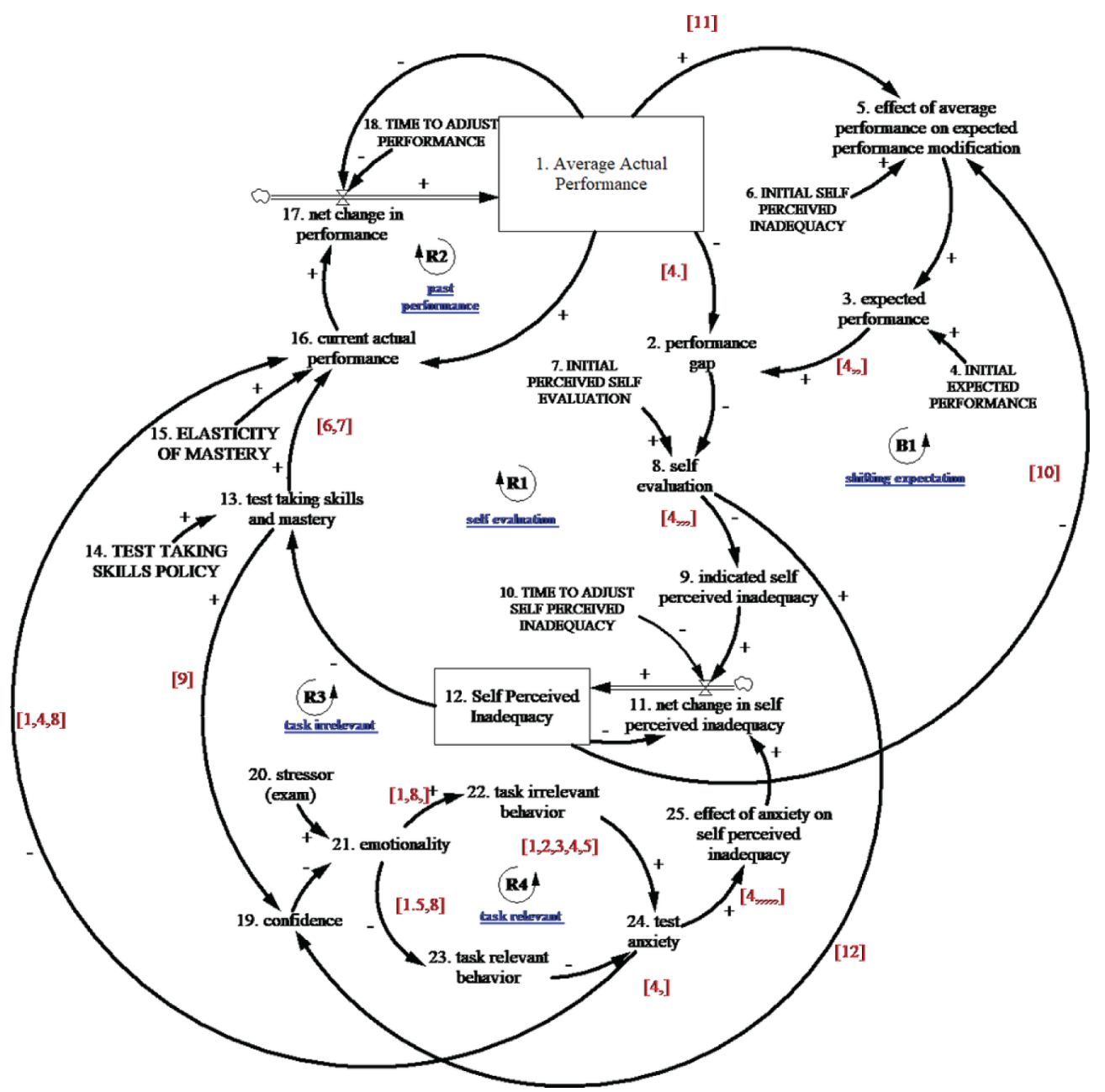

introduced the concept of average actual performance and since we track the cumulative value of this concept, it is referred herein as a stock. The stock of average actual performance changes via net change in performance. Net change in performance is the difference between current actual performance and average actual performance, adjusted by the time it takes to adjust average performance. Likewise, self-perceived inadequacy a concept influenced by students self-evaluation based on performance gap is represented herein as a stock and is changed by the net change in self-perceived inadequacy. Net change in self-perceived inadequacy is herein determined by indicated self-perceived inadequacy and the effect of text anxiety, adjusted by the time and the effect of test anxiety. The self-evaluation influence performance reinforcing feedback loop $(\boldsymbol{R} 1)$ hypothesize that as average actual performance of a student increases, performance gap (which is the difference between expected performance and average actual performance) will decrease, resulting in high self-evaluation and low self-perceived inadequacy. Due to high self-evaluation which consequently results in low self-perceived inadequacy, test-taking skills, and mastery is assumed to increase-here students are assumed to put more effort in preparing for exams due to the increases self-assurance of their ability to perform well. As a result, current actual performance is assumed to increase and consequently average actual performance. The past performance $(\boldsymbol{R} 2)$ reinforcing feedback loop postulate that current actual performance is 
dependent on test taking skills and mastery and average actual performance from previous test (which is a measure of the students past academic performance). As current actual performance increases, average actual performance is assumed to increase which subsequently affect future academic evaluation of the student. The reinforcing feedback loop task-irrelevant (R3) hypothesizes that a high self-perceived inadequacy decreases test-taking skills—as students are more likely to be unprepared for exams-leading to low confidence. A student with low confidence in a stressor environment (exam) is assumed to exhibit emotionality which causes the student to engage in task irrelevant activities leading to test anxiety and further self-doubt, thus reinforcing self-perceived inadequacy. The task-relevant $(\boldsymbol{R} 4)$ reinforcing feedback loop is similar to the reinforcing feedback loop R3 which assumes that low self-perceived inadequacy increases/improves test-taking skills and consequently confidence. Confident students are assumed to experience low levels of emotionality in a stressor environment (exam), as a result, such student tend to engage in task relevant activities, which avoids the tendency to experience test anxiety further reinforcing their self-believe by lowering their selfperceived inadequacy. The shifting expectation (B1) feedback loop postulate that a student with low self-perceived inadequacy due to poor performance is likely to adjust his/her expected performance down, which will then decrease the performance gap and improve self-evaluation.

\section{SIMULATION EXPERIMENTS}

For this model, we simulate four scenarios-high performing student, low performing student, test taking skills policy on low performing student, low expectation for low performing student- to test the ability of the model to generate a range of realistic trajectories by modifying these parameters: (1) initial actual performance; (2) initial expected performance; (3) initial self-evaluation; and (4) initial self-perceived inadequacy (Table 3).

Table 3. Simulation experiments inputs

\begin{tabular}{|l|l|l|l|l|}
\hline \multicolumn{1}{|c|}{ Parameter } & \multicolumn{1}{|c|}{$\begin{array}{c}\text { High- } \\
\text { performing }\end{array}$} & \multicolumn{1}{|c|}{$\begin{array}{c}\text { Low- } \\
\text { performing } \\
\text { performing } \\
\text { with Test } \\
\text { taking skills }\end{array}$} & $\begin{array}{c}\text { Low-performing } \\
\text { with low } \\
\text { expected } \\
\text { performance }\end{array}$ \\
\hline Initial expected performance & 100 & 100 & 60 & 60 \\
\hline Initial actual performance & 75 & 45 & 45 & 45 \\
\hline Initial self-evaluation & 0.8 & 0.1 & 0.1 & 0.1 \\
\hline Initial self-perceived inadequacy & 0.1 & 0.7 & 0.7 & 0.7 \\
\hline Initial test taking skills and mastery & 0.75 & 0.55 & 0.65 & 0.55 \\
\hline
\end{tabular}

- High-performing student: This experiment simulates the test score (average actual performance) and self-perceived inadequacy trajectory of a high-performing student. For the purpose of this experiment, we assume that a high-performing student will have a high initial expected performance (100), relatively high actual initial average actual performance (75), high initial self-evaluation (1) and very low initial self-perceived inadequacy (0.1).

- Low-performing student: The experiment simulates the performing (average actual performance and self-perceived inadequacy) of a low-performing student. Here we assume that such a student will have high initial expected performance (100), relatively low actual initial average actual performance (55), low initial self-evaluation (0.1) and very high initial self-perceived inadequacy (0.9). 
- Low-performing student tutored to improve test-taking skills and mastery: This experiment simulates the performance (average actual performance and self-perceived inadequacy) of a lowperforming student who received significant help in test taking skills-that is assumed to help him/her to perform better over time. Here we assume that such a student will have high initial expected performance (100), relatively low actual initial average actual performance (55), low initial self-evaluation (0.1) and very high initial self-perceived inadequacy (0.9). However, the test-taking skills of the student is assumed to increase overtime leading to better current actual performance.

- Low-performing student with low initial expected academic performance: Here we simulate the performance (average actual performance and self-perceived inadequacy) of a low-performing student who receives a new intervention that focuses on lowering their expectation of actual performance, such a student, we assume will have low initial expected performance (60), relatively low actual initial average actual performance (55), low initial self-evaluation (0.1) and very high initial self-perceived inadequacy (0.9).

As such, due to the aforementioned experiment conditions, the following numbers are assumed for respective simulations.

\section{Results}

Figures 2 shows the average academic performance of a representative student under the four hypothetical experiments. Under the high performing student experiment, a student with an initial average academic performance of $75 \%$ is expected to improve his/her performance

Figure 2. Average actual performance

\section{Average Academic Performance}

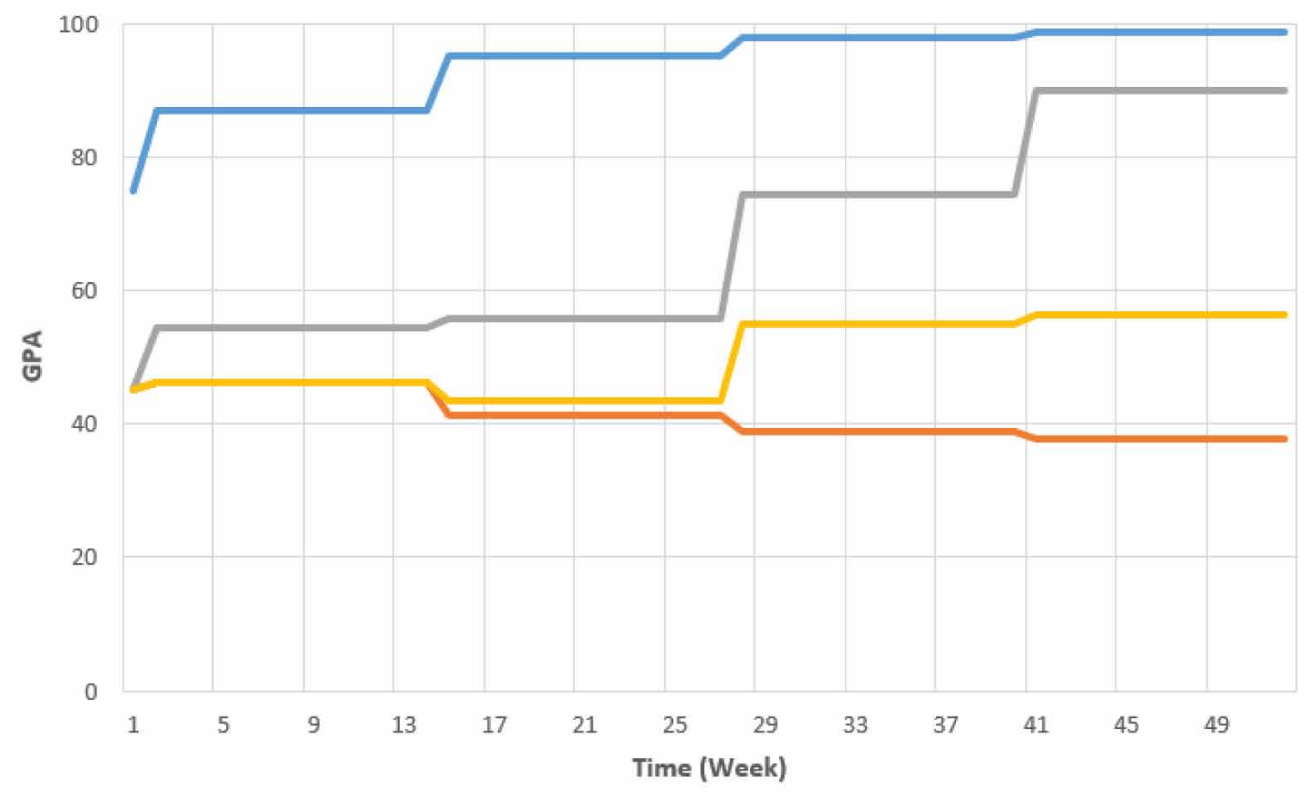


over time and achieve about $98 \%$ at the end of the simulation-representing an increase of $30 \%$ in average academic performance. For the low performing student experiment, a student with an initial average academic performance of $45 \%$ is expected-under the assumptions of the simulation model-to decline in academic performance overtime to $37 \%$ at the end of the simulation-representing $17 \%$ decline in academic performance. Under the experiment where low performing student, whose initial expected academic performance was significantly reduced from $100 \%$ to $65 \%$, in addition to tutoring the student to specifically improve test taking skills and mastery, the result indicate that with an initial average academic performance of $45 \%$, such a student is likely to increase his/her academic performance overtime and reach a value of $89 \%$, representing an increase of $97.7 \%$ under the assumptions of the model. Likewise, a similar low performing student whose initial expected academic performance was reduced from $100 \%$ to $65 \%$ is expected to improve academic performance from $45 \%$ to $56 \%$ over the simulation time, representing $24 \%$ increase in academic performance.

\section{DISCUSSION AND CONCLUSION}

For this research, we have demonstrated that a parsimonious system dynamics model that captures the hypothesised causal feedback mechanisms of test anxiety among students can simulate a realistic range of students' academic performance over time. The simulated results in Figure 2 can be explained by a sequences of activities and processes via student's evaluation of their academic performance. As student evaluate their academic performance (i.e. compares expected academic performance to actual average academic performance), a bigger performance gap will affect self-evaluation negatively, while small performance gap will increase self-evaluation. A higher self-evaluation will motivate students to study hard to improve test talking skills and mastery while low self-evaluation is assumed to de-motivate students to expend required resources (time and effort) to improve test taking skills and mastery. A lower test taking skills and mastery is expected to increase the likelihood of text anxiety during examination time due to inadequate preparation for the test-which leads to engaging in irrelevant activities during examinations. Consequently, academic performance is affected.

The test anxiety and academic performance for student's model could be used in many ways: firstly, the mode provides a set of testable hypothesis which could be empirically evaluated to inform the modification of the model structure. Secondly, the model could be used to explore leverage points for interventions to improve students' academic performance and self-evaluation, as well as mitigate the prevalence of test anxiety. Lastly, the model could be used to educate student's about how their own self-evaluation affect test taking skills and mastery and consequently academic performance and how they could perceive performance in a way that motivate them to work hard to improve academic performance. Figure 3 shows how important variables (i.e. performance gap, self-evaluation, test taking skills and mastery and test anxiety) change over the simulation time for each scenario tested. The preliminary model-based results generate some insights that policy-makers in the education sector could consider conditional on availability of strong empirical evidence; (a) that self-evaluation of students affects their ability to prepare for examinations which directly impact on their testtaking skills. If this turn out to be true, it is important for educators to identify students with low self-evaluation and provide interventions that will help raise self-evaluation; (b) how students perceive performance gap have consequence on their self-evaluation and their willingness to put in effort to improve test-taking skills. Interventions that help student to positively perceive their performance gap and the ability to recognize the delay between effort and results will keep student improve performance over time. 
Figure 3. Dynamics of test anxiety and academic performance

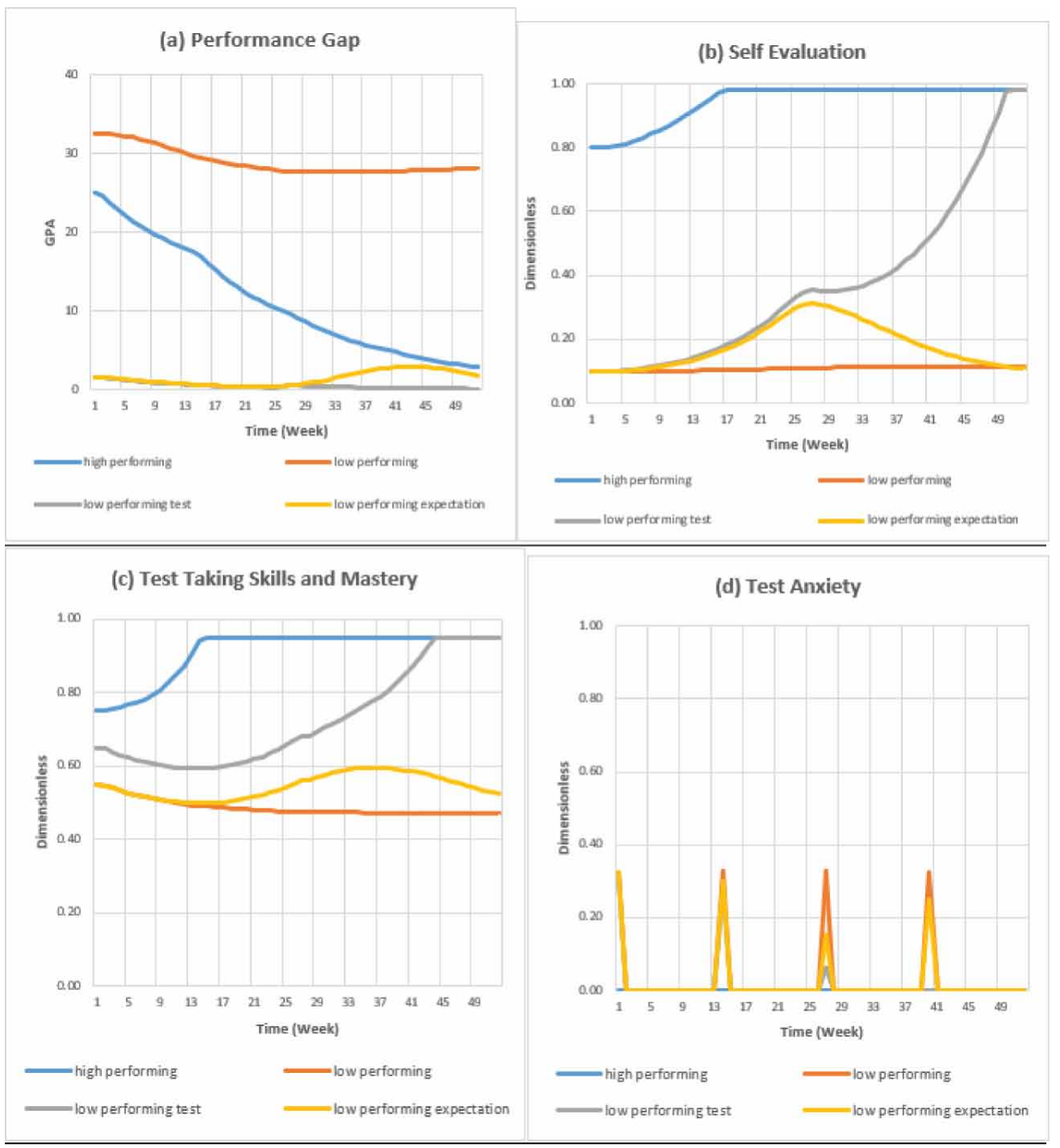

In a competitive society such as Singapore's, it is understandable why students are exposed to and vulnerable to high levels of test anxiety. Not only do the environments impose high expectations on them, but they are also likely to perceive themselves as inadequate against their peers when they do not perform as well. This model can be used as a bounded object to engage students and educators on how to address this important issue. 


\section{REFERENCES}

Al-Kadeem, R., Backar, S., Eldardiry, M., \& Haddad, H. (2017). Review on Using System Dynamics in Designing Work Systems of Project Organizations: Product Development Process Case Study. International Journal of System Dynamics Applications, 6(2), 52-70. doi:10.4018/IJSDA.2017040103

Ansah, J. P. (2017). Causal Analyses of Public Debt and Structural Adjustment. International Journal of System Dynamics Applications, 6(1), 21-37. doi:10.4018/IJSDA.2017010102

Benjamin, M., Mckeachie, W. J., Lin, Y. G., \& Holinger, D. P. (1981). Test anxiety: Deficits in information processing. Journal of Educational Psychology, 73(6), 816-824. doi:10.1037/0022-0663.73.6.816

Bhushan, S. (2017). System Dynamics Base-Model of Humanitarian Supply Chain (HSCM) in Disaster Prone Eco-Communities of India: A Discussion on Simulation and Scenario Results. International Journal of System Dynamics Applications, 6(3), 20-37. doi:10.4018/IJSDA.2017070102

Corbetta, M., \& Shulman, G. L. (2002). Control of goal-directed and stimulus-driven attention in the brain. Nature Reviews. Neuroscience, 3(3), 201-215. doi:10.1038/nrn755 PMID:11994752

Davie, S. (2017). Singapore students suffer from high levels of anxiety: Study. The Straits Times. Retrieved November 23, 2018, from https://www.straitstimes.com/singapore/education/spore-students-suffer-from-highlevels-of-anxiety-study

Driscoll, R. (2007). Westside Test Anxiety Scale Validation. Retrieved January 11, 2019, from https://files.eric. ed.gov/fulltext/ED495968.pdf

Eysenck, M.W., Derakshan, N., Santos, R., \& Calvo, M.G. (2007). Anxiety and Cognitive Performance: Attentional Control Theory. American Psychological Association, 7(2), 336-353. doi: 10.1037/1528-3542.7.2.336

Janis, I. L., \& Field, P. B. (1959). Sex differences and personality factors related to persuasibility. In C. I. Hovland \& I. L. Janis (Eds.), Personality and persuasibility (pp. 55-68). Yale University Press.

Kalechstein, P. B. W., Hocevar, D., \& Kalechestein, M. (1988). Effects of test-wiseness training on test anxiety, locus of control and reading achievement in elementary school children. Anxiety Research, 1(3), $247-261$. doi: $10.1080 / 08917778808248723$

Kirkland, K., \& Hollandsworth, J. G. (1979). Test anxiety, study skills, and academic performance. Journal of College Student Personnel, 431-436.

Lesley, J. (1995). Test Anxiety. Journal of College Student Psychotherapy, 10(1), 3-15. doi:10.1300/ J035v10n01_02

Meichenbaum, D., \& Butler, L. (1980). Toward a conceptual model for the treatment of test anxiety: Implications for research and treatment. In Test anxiety: Theory, research, and applications. L. Erlbaum Associates.

Nasution, F. B., Bazin, N. E., Rosalyn, R., \& Hasanuddin, H. (2018). Public Policymaking Framework Based on System Dynamics and Big Data. International Journal of System Dynamics Applications, 7(4), 38-53. doi:10.4018/IJSDA.2018100103

Organization for Economic Co-operation and Development. (2017). PISA for Development Assessment and Analytical Framework: Reading, Mathematics and Science, Preliminary Version. OECD Publishing.

Posner, M. I., \& Peterson, S. E. (1990). The attention system of the human brain. Annual Review of Neuroscience, 13(1), 25-42. doi:10.1146/annurev.ne.13.030190.000325 PMID:2183676

Rosenberg, M. (2016). Society and the Adolescent Self-Image. Princeton University Press.

Sansgiry, S. S., \& Sail, K. (2006). Effect of students' perceptions of course load on test anxiety. American Journal of Pharmaceutical Education, 70(2), 1-6. doi:10.5688/aj700226 PMID:17149404

Sarason, I. G. (1978). The Test Anxiety Scale: Concept and Research. In C. D. Spielberger \& I. G. Sarason (Eds.), Stress and Anxiety (Vol. 5, pp. 193-216). John Wiley and Sons.

Sarason, I. G. (1980). Introduction to the study of test anxiety. In I. G. Sarason (Ed.), Test anxiety; Theory, research, and application (pp. 3-14). L. Erlbaum Associates. 
Schwarzer, R., \& Jerusalem, M. (1989). Development of test anxiety in high students. In C. D. Spielberger, I. G. Sarason, \& J. Strelau (Eds.), Stress and Anxiety (Vol. 12, pp. 65-79). Academic Press.

Wine, J. D. (1971). Test anxiety and direction of attention. Psychological Bulletin, 76(2), 92-104. doi:10.1037/ h0031332 PMID:4937878

Wittmaier, B. (1972). Test anxiety and study habits. The Journal of Research, 65, 852-854.

Zelinka, D., \& Amadei, B. (2019). Systems Approach for Modeling Interactions Among the Sustainable Development Goals Part 1: Cross-Impact Network Analysis. International Journal of System Dynamics Applications, 8(1), 23-40. doi:10.4018/IJSDA.2019010102 